\title{
Ubudiyah NU Guna Mencegah Ideologi Yang Gemar Menvonis Bid'ah
}

\author{
Nur Sahid1, Muhammad Ma'shum, ${ }^{2}$ \\ 1,2Institut Agama Islam Tribakti Kediri, \\ 1nursahid04@gmail.com,2maksum@iai-tribakti.ac.id,
}

\begin{abstract}
This study aims to describe the NU Ubudiyah applied at Al-Ishlah Islamic boarding school and how to prevent students from ideologies who are fond of convicting heresy. This research uses a qualitative approach with a case study research design. The results stated that NU's strong ideology was tight in Indonesian society at the grassroots level. This ideology is rooted in the traditions of society. Starting from reading Yasin, Tahlil, and others that are difficult to disappear. The tradition is acculturated with the beliefs of Ancient Javanese inherited by Hindu Buddhism.
\end{abstract}

Keywords: NU's Ubudiyah, Ideology, Bid'ah Verdict

\begin{abstract}
Abstrak
Penelitian ini bertujuan untuk mendeskripsikan Ubudiyah NU yang di terapkan di pondok pesantren Al-Ishlah dan cara mencegah santri dari ideologi yang gemar menvonis bid'ah. Penelitian ini menggunakan pendekatan kualitatif dengan rancangan penelitian studi kasus. Hasilnya menyatakan bahwa NU idologi yang kuat mengakat di masyarakat Indonesia di kalangan akar rumput. Ideology tersebut mengakar di dalam tradisi masarakat. Mulai dari membaca Yasin, Tahlil, dan lainnya yang sulit hilang. Tradisi tersebut berakulturasi dengan kepercayaan Jawa Kuno yang diwariskan oleh Hindu Budha.
\end{abstract}

Kata Kunci: Ubudiyah NU, Ideologi, Vonis Bid'ah

\section{Pendahuluan}

Pendidikan memiliki kekuatan

(pengaruh) yang dinamis dalam

kehidupan manusia di masa depan. optimal, yaitu pengembangan potensi individu yang setinggi- tingginya dalam aspek fisik, intelektual, emosional, sosial dan spiritual, sesuai dengan tahap perkembangan serta karakteristik lingkungan fisik dan lingkungan 
sosiobudaya di mana dia hidup.

Pendidikan merupakan suatu fenomena manusia yang sangat kompleks. Karena sifatnya kompleks itu maka pendidikan dapat dilihat dan dijelaskan dari berbagai sudut pandang. ${ }^{1}$

Pendidikan merupakan hak yang harus didapatkan oleh setiap individu, untuk mendapatkan pengetahuan yang seluas-luasnya dan keilmuan yang sebanyak-banyaknya. Saat ini pendidikan di Indonesia telah berkembang secara pesat baik pendidikan formal, non formal maupun in formal.

Salah satu sarana pendidikan keagamaan yang semakin berkembang adalah pondok pesantren. Sebelum tahun 60-an, pusat pendidikan pesantren di Jawa dan Madura dikenal dengan nama pondok. Istilah pondok barangkali berasal dari pengertian asrama-asrama para santri yang disebut pondok atau tempat tinggal yang dibuat dari bambu, atau barangkali berasal dari bahasa Arab funduq, yang berarti hotel atau asrama. ${ }^{2}$

Pesantren merupakan lembaga pendidikan dan pengajaran Islam di
Kyai atau Ustadz sebagai guru dan para santri sebagai murid dengan mengambil tempat di masjid atau di halamanhalaman asrama (pondok) untuk mengaji dan membahas buku-buku teks keagamaan karya ulama masa lalu (kitab kuning). Dengan demikian unsur terpenting bagi sebuah pesantren adalah adanya Kyai, para santri, masjid, tempat tinggal (pondok) serta buku-buku atau kitab-kitab teks.

Pesantren merupakan lembaga tertua dibandingkan dengan lembagalembaga yang ada di Indonesia. Hal ini karena pesantren, yang merupakan lembaga berbasis masyarakat, sudah ada sejak adanya masyarakat Islam Di Nusantara, yaitu pada abad ke $13^{3}$

Ketika pendidikan di pesantren di jalan yang benar, maka setiap Setiap orang tidak hanya dituntut untuk beriman, tetapi juga dituntut untuk beramal sholeh. Karena Islam adalah agama amal, bukan hanya keyakinan. Ia tidak hanya terpaku pada keimanan semata, melainkan juga pada amal

3 M. Sulthon Masyhud, dkk, Manajemen Pondok Pesantren (Jakarta: Diva Pustaka, 2005), Cet. II, 1.
(Jakarta : Universitas Terbuka, 2009), hal. 1-2

2 Zamakhsyari Dhofier, Tradisi Pesantren:

Studi Tentang Pandangan Hidup Kyai (Jakarta:

LP3S, 1982), 18. 
perbuatan yang nyata. Islam adalah kepercayaan anismisme memuja roh agama yang dinamis dan menyeluruh. yang dipercaya mepunyai pengaruh Dalam Islam, Keimanan harus terhadap kehidupan manusia. Mereka diwujudkan dalam bentuk amal yang yang beragam dinamisme memuja nyata, yaitu amal sholeh yang dilakukan kekuatan yng terdapat pada benda-benda karena Allah. Ibadah dalam Islam tidak tertentu yang dipandang keramat.

hanya bertujuan untuk mewujudkan Hal di atas terjadi karena hubungan antara manusia dengan manusia pada dasarnya mencari jalanya Tuhannya, tetapi juga untuk sendiri untuk memenuhi tuntutan unsur mewujudkan hubungan antar sesama manusia. Islam mendorong manusia untuk beribadah kepada Allah SWT dalam semua aspek kehidupan dan aktifitas. Baik sebagai pribadi maupun sebagai bagian dari masyarakat. Ada tiga aspek fungsi ibadah dalam Islam.

Ibadah merupakan unsur mutlak dalam agama. Agama yang sejatinya adalah keyakinan tentang adanya zat yang berkuasa di atas alam raya, dan kerinduan manusia untuk menggunakan dan berhubungan dengan-Nya, melahirkan berbagai macam cara pengabdian, pemujaan dan ibadah.

Dalam mengimplementasikan keyakinannya, bangsa-bangsa didunia ini mempunyai cara sendiri-sendiri dalam beribadah kepada zat yang berkuasa di atas alam ini. Misalnya, para penganut perasaanya. Oleh karena itu, Allah mengajarkan bahwa pentingnya diutus para rosul untuk memberi petunjuk tentang siapa yang berhak disembah dan bagaimana cara melakukan penyembah kepada-Nya. ${ }^{4}$

Umat islam, umat Al-Qur'an umat Muhammad saw, harus mengikuti ketentuan agama, menetapkan segala batasan dan segala yang Dia syari'atkan untuk hambanya, berkomitmen dengannya, tidak menambah dan tidak mengurangi. Meskipun bersikap mengikuti ketentuan agama, umat juga membuat pembaruan dalam urusan duniawi, seperti pembaruan dalam ilmu bahasa dan sastra, serta dalam ilmu puisi dan sastra. Umat islam juga berhasil melahirkan ilmu nahwu, ilmu sharaf, ilmu balaghoh. Selain itu mereka juga 
melahirkan beragam ilmu agama, antara lain fiqih, ilmu Al-Qur'an, ilmu hadist. Mereka juga melahirkan ilmu aljabar dan sangat berkontribusi dalam berbagai bidang ilmu, baik ilmu alam, matematika, maupun sosiologi ${ }^{5}$.

Pada era modern ini dunia Islam menghadapi krisis serangan yang bertubi-tubi dari pada penentangnya. Tak hanya menghadapi serangan dari kubu luar, serangan dari dalam pun begitu derasnya menghantam dunia islam.

Serangan mereka yang paling menyakitkan adalah upaya-upaya untuk mengacaukan kaum muslimin, mereka dengan lantang meneriakan "ini adalah pembaruan dan modernisasi", mereka juga memprogandakan kepada masyarakat bahwa ajaran yang mereka bawa adalah yang paling sesuai dengan al-qur'an dan as-sunnah. Terbukti hal ini memiliki efek besar sehingga akhirnya tidak sedikitpun kaum muslimin yang merasa seakan-akan meminum obat, padahal yang mereka tenggak adalah racun. Kaum muslimin yang tertipu itu merasa teracuni sehingga memaksa kaum

5 Yusuf al-qaradhawi, Bid'ah Dalam Agama, (Jakarta: Gema Insani, 2014), xv

${ }^{6}$ Forum Kajian Ilmiah Angkatan 2014, Potret Ajaran Nabi Muhammad Dalam Sikap Santun muslimin yang lain untuk mengikuti gerakan tersebut. Mereka juga angkat suara dengan propaganda yang kurang lebih sama untuk menarik simpati dari dunia islam.

Ironisya, ajaran serta visi mereka yang berkedok kembali al-qur'an dan assunnah itu mereka jadikan senjata ampuh untuk meruntuhkan amalan-amalan yang sudah dengan sukses di da'wahkan oleh wali songo menjadi semacam tradisi yang kuat dan terus di amalkan oleh masyarakat negara kita khususnya warga NU dengan bimbingan dari para ulama dan kiyai pembimbing kita. ${ }^{6}$

Selama ini, banyak orang, kalangan dan kelompok yang mempertanyakan paham NU, baik akidah maupun amaliyahnya. Di tengah masyarakat, muncul "serangan-serangan yang menggugat tata cara ibadah dan tradisi keislaman yang dilakukan warga NU, seperti maulud Nabi, Tahlilan, Istighosah, Tawasul, dan lain sebagainya. Kaum nahdiyin yang mencerminkan mayoritas umat islam di Indonesia merasa terganggu dengan adanya cap bid'ah, syirik, pada amaliayah yang telah

Tradisi Dan Amalia, (Kediiri: Sumenang , 2014 ), VII 
menjadi kebiasaan mereka tersebut. pendidikan tradisional Islam di Jawa dan Selain itu muncul pula kelompok dan Madura. $^{7}$

aliran yang tidak sesuai dengan paham

Kata santri juga tidak pernah aswaja yang menjadi keyakinan NU. Tak jarang paham-paham tersebut lepas dari bahasan pondok pesantren, mempengaruhi pikiran warga nahdiyin.

\section{Kajian Teori \\ Pondok Pesantren}

Pondok Pesantren terdiri dari dua kata yakni pondok dan pesantren. Istilah pesantren, terutama di Jawa dan Madura muncul pada 1960-an. Sebelumnya, nama pondok lebih popular dibanding istilah pesantren. istilah "pondok" berasal dari pengertian asrama-asrama para santri atau tempat tinggal yang dibuat dari bambu, atau istilah "pondok" yang berasal dari bahasa Arab, funduq, yang berarti hotel atau asrama. Istilah pesantren menurut Kamus Besar Bahasa Indonesia berarti, "asrama tempat santri atau tempat murid belajar ngaji" akar kata pesantren berasal dari kata "santri", yaitu istilah yang pada awalnya digunakan bagi orang-orang yang menuntut ilmu agama di lembaga

7 Anwar Ali, Pembaharuan Pendidikan di Pesantren Lirboyo Kediri (Kediri: IAIT Pres 2008), 22. 
kepribadian Nabi Muhammad (mengikuti sunah Nabi). ${ }^{9}$

Pesantren merupakan lembaga pendidikan Islam di mana di dalamnya terdapat interaksi antara kyai dan ustadz sebagai guru dan santri sebagai murid dengan mengambil tempat di masjid atau halaman-halaman asrama (pondok) untuk mengaji dan membahas bukubuku teks keagaman karya ulama masa lalu (kitab kuning). Adapun secara historis awal mula kemunculan pesantren masih kabur, banyak sekali penulis yang berbeda pendapat bahwa instituti ini merupakan hasil adopsi dari model perguruan yang diselenggarakan oleh orang-orang Hindu dan Budha. Islam datang dan berkembang di pulau Jawa telah ada lembaga perguruan Hindu dan Budha yang menggunakan sistem biara dan asrama sebagai tempat para pendeta dan biksu melakukan kegiatan pembelajaran kepada para pengikutnya. ${ }^{10}$

\section{Ubudiyah}

\footnotetext{
${ }_{9}$ Mujamil Qomar, Pesantren dari transformasi Metodologi Menuju Demokratisasi Intitusi, (Jakarta: Erlangga ), 3

${ }^{10}$ Anason mengungkapkan bahwa "Sebagian ahli sejarah memperkirakan masuknya Islam ke Indonesia dimulai sejak abad ketujuh, sebgaian lain memperkirakan bahwa Islam telah mulai berkembang di Indonesia sekitar abad ke-
}

Ibadah berasal dari kata arab ibadah, yang bersifat pengabdian, penghambaan, ketundukan, dan kepatuhan. Dari akar yang sama kita mengenal $a b d$ (hamba, budak) yang menghimpun makna kekurangan, kehinaan, dan kerendahan. Karena itu ibadah ialah pengungkapan rasa kekurangan, kehinaan, dan kerendahan diri dalam bentuk penganggungan, penyucian dan syukur atas segala nikmat. Kata abd diserap keddalam bahasa Indonesia menjadi abdi, seorang yang mengabdi dengan tunduk dan patuh kepada orang lain. Dengan demikian segala bentuk sikap pengabdian dan kepatuhan merupakan ibadah walaupun tidak dilandasi suatu keyakinan.

Sedangkan dasar hokum ibadah itu antara lain firman Allah dalam Surat al Baqoroh ayat 21 "Hai manusia, sembahlah Tuhanmu yang telah menciptakanmu dan orang-orang yang sebelummu, agar kamu bertakwa".

11, dengan salah satu bukti yang paling kuat, yaitu ditemukannya batu nisan Fatimah binti Maimun bin Hibatullah yang wafat pada 457 atau 1082 M. di lereng Gresik Jawa Timur. Anason, "Sejarah Masuknya Islam di Jawa" dalam Darrari Amin (ed. ), Islam dan Kebudayaan Jawa (Yogyakarta: Gadjah Mada, 2002), 28. 
Al-quran mengajarkan bahwa jin dan manusia diciptakan Allah agar mereka beribadah kepadanya. Ajaran di atas memberi pengertian bahwa ibadah bukan hanya berupa shalat, zakat, puasa, dan haji, seperti yang dipahami banyak orang, karena ibadah mempunyai pengertian yang lebih luas.

Ibadah dalam pengertian yang umum adalah menjalani kehidupan untuk memperoleh keridhaan Allah dengan mentaati syariatnya. Apabila dikerjakan dengan tujuan memperoleh keridhaan Allah, segala perbuatan merupakan ibadah dalam arti yang umum. Menunaikan hak individu sesuai dengan perintah Allah dan Rosulnya seperti makan, minum, menuntut ilmu adalah ibadah. ${ }^{11}$

Apabila diteliti dan direnungkan, setiap ibadah dalam islam pasti mengandung hikmah. Oleh karena itu, dalam memberikan gamabaran ibadah yang bersifat final, islam menggariskan prinsip-prinsip ibadah sebagai berikut.

1. Yang berhak disembah hanya Allah.

2. Ibadah tanpa perantara.

3. Ikhlas sendi ibadah yang akan diterima.

4. Ibadah sesuai dengan ketentuan.
5. Memelihara keseimbangan antara unsur rohani dan jasmani

6. Mudah dan meringankan. ${ }^{12}$

Sebagaimana yang telah diuraikan diatas, bahwa ibadah itu adalah tugas dan kewajiban hidup manusia selama hidup dalam kehidupan dunianya selagi dikarunia akal. Ibadah itu sebagai perwujudan status dirinya sebagai makhluk allah yang paling mulia, oleh karena itu setiap manusia tidak diperkenankan beribadah kecuali hanya kepada Allah SWT semata, sebab makhluk lain lebih rendah kedudukanya dari pada manusia.

Ibadah merupakan ikatan kehambaanya kepada sang Khaliq di mana ketika seorang hamba beribadah berarti telah menghinakan dirinya dirinya dihadapan Tuhanya dan memulyakan zat yang sedang disembahnya, maka hakikat ibadah adalah kesadaran diri hina dihadapan Allah yang mulia dan hanya dia yang patut diibadahi.

\section{Bid'ah}

Siapapun yang menelaah kembali kamus bahasa Arab, baik yang 
ringkas, yang pertengahan, maupun yang besar, akan mendapati bahwa para penyusun kamus tersebut sepakat dalam pengertian bid'ah. Meskipun terkadang ungkapan mereka berlainan, namun meiliki makna yang sama.

Penyususn kamus al-Mu'jamul Wasiith mengatakan bid'ah adalah apa yang diadakan dalam agama lainya. Penyusun kamus al-Qaamuus mengatakan bi'ah adalah membuat hal baru dalam agama setelah sempurnanya agama. Atau sesuatu yang diada-adakan setelah nabi saw. Baik berwal dari hawa nafsu maupun amal perbatan. Jadi setiap hal yang diadakan dalam urusan dunia ataupun agama, tanpa ada contoh sebelumnya adalah bi'ah.

Tidak semua yang dianggap bid'ah secara bahasa menjadi bid'ah secara syariat. Terkadang sesuatu hal dinilai bid'ah dan orang-orang menyebut sebagai bid'ah dari sisi bahasa, tetapi sesuatu itu terpuji secara syariat. ${ }^{13}$

Ibnu Abdussalam juga memberikan contoh pada setiap bid'ah diantara bid'ah tersebut dengan mengatakan bid'ah adalah melakukan sesuatu yang tidak pernah dilakukan pada masa Rosulullah SAW. Bid'ah terbagi dalam bid'ah wajib, bid'ah haram, bid'ah musatabah, bid'ah makruh, dan bid'ah mubah. Cara untuk menegetahuinya adalah dengan mengharapkan bid'ah pada kaidahkaidah syari'ah. Jika bid'ah masuk dalam kaidah-kaidah wajib, itu bid'ah wajib. Jika bid'ah masuk dalam kaidah-kaidah haram, itu bid'ah haram. Jika bid'ah masuk dalam kaidah-kaidah mustabah, itu bid'ah mustabah. Jika masuk dalam kaidah-kaidah makruh, itu bid'ah makruh. Jika masuk dalam kaidahkaidah nubah, itu bid'ah mubah. ${ }^{14}$

\section{Ideologi.}

Istilah idelogi berasal dari kata 'idea' yang berarti gagasan konspe, pengertian dasar, cita-cita dan logos yang berarti ilmu. Kata 'idea' berasal dari Bahasa Yunani 'eidos' yang artinya bentuk. Disamping itu ada kata 'idien' yang artinya melihat. Maka secara harfiah, ideologi berarti ilmu pengertianpengertian dasar. Dalam pengertian sehari-hari, 'idea' disampaikan artinya dengan cita-cita. Cita-cita yang dimaksud adalah cita-cita yang bersifat tetap yang

13 Yusuf al-qaradhawi, Bid'ah Dalam

14 Yusuf al-qaradhawi, Bid'ah Dalam 
harus di capai sehingga cita-cita yang bersifat tetap itu sekaligus merupakan dasar, pandangan atau faham. Memang pada hakikatnya, antara dasar dan citacita itu sebenarnya dapat merupakan satu kesatuan. Dasar di tetapkan karena suatu landasan, asas atau dasar yang telah di tetapkan pula. Dengan demikian Ideologi mencangkup pengertian tentang ide-ide, pengertian dasar, gagasan dan cita-cita. ${ }^{15}$

\section{Kesimpulan}

NU idologi yang kuat mengakat di masyarakat Indonesia di kalangan akar rumput. Ideology tersebut mengakar di dalam tradisi masarakat. Mulai dari membaca Yasin, Tahlil, dan lainnya yang sulit hilang. Tradisi tersebut berakulturasi dengan kepercayaan Jawa Kuno yang diwariskan oleh Hindu Budha.

\section{Daftar Pustaka}

al-qaradhawi, Yusuf. Bid'ah Dalam Agama, Jakarta: Gema Insani, 2014

Anason, "Sejarah Masuknya Islam di Jawa" dalam Darrari Amin (ed. ), Islam dan Kebudayaan Jawa Yogyakarta: Gadjah Mada, 2002

Anwar, Ali. Pembaharuan Pendidikan di Pesantren Lirboyo Kediri Kediri: IAIT Pres 2008
Dhofier, Zamakhsyari. Tradisi Pesantren: Studi Tentang Pandangan Hidup Kyai, Jakarta: LP3S, 1982

Forum Kajian Ilmiah Angkatan 2014, Potret Ajaran Nabi Muhammad Dalam Sikap Santun Tradisi Dan Amalia, Kediri: Sumenang , 2014

Masyhud, M. Sulthon dkk. Manajemen Pondok Pesantren Jakarta: Diva Pustaka, 2005

Munir, Salamah, dan Suratman, Pendidikan Pancasila, Malang: Madani Media, 2016

Nor, Huda. Islam Nusantara, Jogjakarta: Ar-Ruzz Media, 2007

Qomar, Mujamil. Pesantren dari transformasi Metodologi Menuju Demokratisasi Intitusi, Jakarta: Erlangga

Taufik, Agus. dkk, Pendidikan Anak di SD, Jakarta : Universitas Terbuka, 2009

Tono, Sidik Dkk, Ibadah Dan Akhlak Dalam Islam, Yogyakarta: UII Pres Indonesia, 1998

${ }^{15}$ Munir, Salamah, dan Suratman, Pendidikan Pancasila (Malang: Madani Media, 2016), 53 